Revista de Estudios Histórico-Jurídicos

[Sección historia de las instituciones]

XL (Valparaíso, Chile, 2018)

[pp. 617 - 643]

\title{
EL SISTEMA DE DERECHO PROBATORIO BAJO MEDIEVAL DE las Siete Partidas y las Federal Rules of EVIDENCE DE 1975: DOS ESTRATEGIAS PARA UN MISMO PROPÓSITO
}

[The Late Medieval Law System of Evidence of the Seven-part Code and the Federal Rules of Evidence of 1975: Two Strategies for the Same Purpose]

\author{
Johann S. BENFELD EsCobaR* \\ Jorge A. Larroucau Torres** \\ Pontificia Universidad Católica de Valparaíso, Chile***
}

\begin{abstract}
RESUMEN
El sistema de prueba tasada o legal debe su origen al desarrollo científico del derecho probatorio realizado por los juristas de la Baja Edad Media. Aquéllos, con el propósito de aportar insumos para la resolución oportuna y pacífica de los conflictos jurisdiccionales, desarrollaron textos doctrinales ricos en recursos pedagógicos, teóricos y prácticos. Entre
\end{abstract}

\begin{abstract}
The system of weighing evidence emerges from the scientific development of the law of evidence performed by the Lower Middle Ages' lawyers who, in order to provide inputs for the timely and peaceful resolution of jurisdictional conflicts drafted doctrinal texts with significant pedagogical, theoretical and practical resources. Among the texts written in this period, The Seven-
\end{abstract}

ReCiBido el 5 de diciembre de 2017 y aCEPTADO el 13 de julio de 2018

* Licenciado en Filosofía por la Universidad Católica de Valparaíso, Chile; Licenciado en Ciencias Jurídicas por la Pontificia Universidad Católica de Valparaíso, Chile. Doctor en Derecho por la Universidad de Salamanca, España. Profesor de teoría y filosofía del derecho de la Pontificia Universidad Católica de Valparaíso. Dirección postal: Facultad de Derecho, Pontificia Universidad Católica de Valparaíso, Avda. Brasil 2950, Valparaíso, Chile. Correo electrónico: johann.benfeld@pucv.cl.

** Licenciado en Ciencias Jurídicas y Sociales por la Universidad de Concepción. Doctor en Derecho por la Universidad de Chile. Profesor de derecho procesal de la Pontificia Universidad Católica de Valparaíso. Dirección postal: Facultad de Derecho, Pontificia Universidad Católica de Valparaíso, Avda. Brasil 2950, Valparaíso, Chile. Correo electrónico: jorge.larroucau@pucv.cl.

*** Este artículo forma parte del proyecto Fondecyt de iniciación No 11160046, titulado "Formulación de un concepto jurídico alternativo de reglas de sana crítica en materia probatoria y sistematización de los criterios y de las reglas particulares a él asociadas", del cual uno de los autores es investigador principal. ABREVIATURA: FRE=Federal Rules of Evidence. 
los textos de este período merece una mención especial el código de las Siete Partidas de Alfonso X; documento que recoge, como pocos, los principios y reglas propios del incipiente derecho probatorio continental. A su vez, y siguiendo un camino teórico diverso, en el contexto anglosajón la llamada tradición racional de la prueba judicial-cuyos inicios coinciden con la época moderna-también desarrolló textos doctrinales, teóricos y prácticos de inestimable valor para el derecho probatorio, una de cuyas expresiones normativas más logradas son las Federal Rules of Evidence estadounidenses de 1975. En este trabajo sostenemos que entre ambas tradiciones y textos es posible advertir, contrario a lo que se afirma habitualmente, importantes puntos de contacto, sobre todo en lo que se refiere a la relación entre los principios y reglas probatorias con los fines propios del procedimiento judicial.

\section{Palabras clave}

Derecho probatorio - Tradición probatoria bajo medieval - Tradición racional de la prueba - Siete Partidas Federal Rules of Evidence.
Part Code -compiled during the reign of Alfonso X-deserves special mention, since this is one of the few texts that gathers the principles and rules inherent to the emerging Continental Law of Evidence. The so called rationalist tradition of the law of evidence (an Anglo Saxon theoretical perspective) is consistent with modern times and also developed doctrinal, theoretical and practical texts of priceless value for law of evidence, among which is the Federal Rules of Evidence of 1975 of the United States of America. In this work we propose that there are important points of contact between both traditions and among such texts, unlike what is commonly asserted, especially regarding the relationship between the principles and rules of evidence with the ends inherent to the legal procedure.

\section{Keywords}

Law of evidence - Late Medieval evidence production tradition - Rationalist tradition of the evidence - Seven-Part Code - Federal Rules of Evidence.

\section{Planteamiento de la Cuestión}

William Twining, en Rethinking Evidence, entrega un listado de nueve características propias de lo que él denomina la tradición racional de la prueba (rational theories of evidence and proof: some common assumptions). Resumiendo mucho las cosas, estas notas son: la convicción de que el conocimiento de los hechos pasados es posible; que el establecimiento de la verdad como correspondencia de los hechos (dentro de un proceso) es la condición necesaria para la justicia del caso particular; que existe una comunión necesaria y racional entre la verdad de los hechos y la decisión justa (en el derecho vigente); que a falta de juicios absolutos en materia de hechos a probar, ha de recurrirse al cálculo de probabilidades; que el uso instrumental del cálculo de probabilidades debe ser realizado en términos racionales (justificados); que las probabilidades han de interpretarse siempre en términos de la natural ocurrencia de los hechos (sentido común) y de acuerdo con el estado actual de la ciencia; que en materia probatoria la búsqueda de la verdad debe tener prioridad frente a otros fines del proceso (seguridad del Estado, el orden de las familias, la protección de garantías individuales, etc.); que la evaluación de las reglas probatorias y de procedimiento probatorio han de juzgarse por su eficacia en la obtención de la verdad más que por otros criterios y valores disponibles en 
el sistema (celeridad, economía, etc.); y que la psicología forense y la ciencia del procedimiento deben esforzarse en proveer a los operadores jurídicos (sobre todo al juez) métodos fiables para la búsqueda de la verdad de los hechos ${ }^{1}$.

La caracterización que realiza Twining de la teoría racional de la prueba tiene, a lo menos, dos propósitos. El primero es definir los parámetros (criterios y fines) que ha de satisfacer una teoría r a c i o n a l de la prueba. El segundo, conectado con el anterior, es distinguir la tradición racional de la prueba de lo que se puede denominar formalis mo probatorio (cuyo origen supuestamente se encontraría en los textos procesales bajo medievales), caracterizado por el establecimiento de reglas probatorias de carácter oblig a to ri o sobre admisión, diligenciamiento, exclusión y ponderación de la prueba ${ }^{2}$.

Es precisamente en contra del formalismo probatorio que la tradición racional de la prueba desarrolla sus argumentos y define el campo de batalla. Y escenas como las descritas por Bentham en su Tratado de las pruebas judiciales, por ejemplo en el caso Wilkes, abonaron el terreno para que el llamado movimiento abolicionista de la prueba ${ }^{3}$, sobre el que más adelante volveremos, dirigiera todo tipo de reproches al antiguo sistema probatorio que, empero y muy a su pesar, aún pervive en los sistemas probatorios del Common law y del Civil law.

La tesis de la falta de racionalidad de la regulación premoderna, personificada generalmente en la tradición probatoria bajo medieval (por su pretendido forma-

${ }^{1}$ TwInING, William, Rethinking Evidence. Exploratory Essays (2a ed., [s.l., pero Cambridge], Cambridge University Press, 2006), p. 76.

${ }^{2}$ En esto Twining sigue en la senda trazada por Bentham. Es conocida la aversión que aquél tenía por el formalismo jurídico, rechazo que quedó inmortalizado en una célebre nota al pie del Título Primero del "Tratado sobre las pruebas judiciales", donde en el contexto de lo que Bentham denomina "la locura de la erudición", se puede leer lo siguiente: "estaba yo presente en el Tribunal del banco del rey, en la sala Westminster, cuando el célebre Wilkes, después de haberse sustraído algún tiempo a la sentencia que esperaba, se presentó de improviso para recibirla. No es fácil imaginar hasta qué punto esta comparecencia inesperada sorprendió y confundió a los jueces. La forma procesal requería, no que se presentase él mismo, sino que apareciese remitido por el sheriff; fallando esta forma, el desconcierto de la justicia era verdaderamente cómico. Al fin se le dijo: 'señor, particularmente quiero creer que usted se encuentra ahí, ya que usted lo dice y yo lo veo; pero no existe ningún antecedente de que la corte, en situación parecida, haya creído que debía fiarse de sus propios ojos; por tanto, nada tiene que decirnos'. ¿Quién le dirigía ese discurso? Uno de los más grandes genios de Inglaterra; mas ¿de qué sirve el genio cuando se encuentra oprimido por reglas que obligan a que un hombre tenga ojos y no vea y orejas y no oiga?”. BEnTHAm, Jeremy, Treatise of Judicial Evidence by M. Dumont (London, Messrs. Baldwin, Cradock and Joy, 1825), p. 6. El célebre Wilkes es John Wilkes (1725-1797); y el sabio juez al cual se refiere la cita es lord Mansfield (William Murray, 1st Earl of Mansfield, 1705-1793). Véase también, Bentham, Jeremy, The Works of Jeremy Bentham (published under the Superintendence of his Executor John Bowring) (London, Simpkin, Marshall \& Co., 1843), VII, pp. 45-46.

${ }^{3}$ Para una comprensión sobre el llamado movimiento abolicionista de la prueba, sus luces y sombras, véase STEIN, Alex, Foundations of Evidence Law ([s.l., pero Oxford], Oxford University Press, 2005), capítulo IV. Stein advierte y denuncia la paradoja que presenta el abolicionismo en materia de derecho probatorio: pretendiendo $\mathrm{m}$ o $\mathrm{d}$ e $\mathrm{r} \mathrm{n}$ i z a r la disciplina del Evidence Law no ha hecho otra cosa que retrotraer a un estadio pre-científico al derecho probatorio anglosajón (véanse especialmente pp. 108-113). 
lismo) no significa, por cierto, que para los a b o $\mathrm{l}$ i c i o $\mathrm{n}$ is t a s los jueces deban obrar a su arbitrio en la fase probatoria de un proceso judicial. De ahí que dentro de la propia tradición racional los teóricos se hayan animado a formular principios probatorios de los cuales, a su vez, es posible derivar algunas reglas de prueba. En tal sentido, Anderson, Schum y el propio Twining, en Analysis of Evidence, dan cuenta de un conjunto de $\mathrm{p} r$ in ci p i os $\mathrm{rac}$ i o $\mathrm{n}$ a les del derecho probatorio.

Para entender su estrategia es necesario aclarar el concepto de racionalidad con el que trabaja la tradición racional de la prueba. Según los autores recién citados la r a c i o n a li d a d probatoria "encontró su expresión clásica en la filosofía empírica inglesa, en los escritos de Bacon, Locke y John Stuart Mill”“. En consecuencia, se trata de una concepción particular de racionalidad que dejaría fuera o $\mathrm{t} r$ a s dimensiones de la razón especulativa y práctica. Pues bien, en el uso de esta racionalidad empírica un principio probatorio se define -en su núcleocomo una base epistemológica "para construir argumentos que logren persuadir a una corte que la posición del abogado es consistente con los supuestos en los que se basa el sistema, a diferencia de la de su contraparte" ${ }^{5}$. En el contexto de la tradición racional esta idea esencial se descompone en cuatro principios de la actividad probatoria: un primer principio rector, denominado r e ctit ud de l a d e c i s i ó $\mathrm{n}$, respecto del cual se alinean otros tres principios: la búsqueda de la verdad; la prioridad epistemológica de la verdad por sobre otros fines; y la realización de la justicia mediante la aplicación del derecho vigente al caso particular en base a hechos verdaderos ${ }^{6}$.

Estos principios, a su vez, son vistos por la tradición racionalista como ideas regulatorias (i. e., aspiraciones del sistema), lo que se manifiesta en una legítima aspiración de los actores del sistema probatorio en orden a obtener una recta decisión.

A estos principios racionales del diseño jurídico probatorio se añaden una constelación de estrategias propias de la lógica deductiva (inferencias del todo a la parte), inductiva (inferencias y generalizaciones de la parte al todo) y abductiva (formulación de hipótesis e inferencias dentro de lo posible y de lo probable). Estos principios y métodos aportan, en el contexto de la tradición racional de la prueba, el fundamento teórico científico que la teoría demanda para interpretar las prácticas probatorias.

De lo dicho hasta aquí resulta claro que la denominada tradición racional de la prueba (TR), por una parte, se caracteriza por algunas notas distintivas y, por otra, se distingue de su contraparte bajo medieval (BM) en algunas ideas relevantes, dentro de las cuales cabe destacar: el concepto de racionalidad (deductivo conceptual (BM)/inductivo empírico (TR)) y el método empleado para la determinación de la verdad de los hechos (escolástico (BM)/científico inductivo (TR)). Sin embargo, llama la atención -como veremos más adelante- que los

\footnotetext{
${ }^{4}$ Anderson, Terence; Schum, David; Twining, William, Análisis de prueba (traducción castellana de Daniela Accatino et al., Madrid-Barcelona-Buenos Aires-São Paulo, Marcial Pons, 2015), p. 119.

${ }^{5}$ Ibíd., p. 116.

${ }^{6}$ Ibíd., pp. 116-117.
} 
principios inspiradores y las reglas particulares en una y otra tradición guardan una gran semejanza ${ }^{7}$.

En este trabajo afirmamos que estas semejanzas no son simples coincidencias, sino que responden a una razón más profunda: la dependencia conceptual del derecho probatorio, sus principios y reglas, de los compromisos éticos presentes en los fines del proceso judicial. En este sentido, la finalidad de resolver pacíficamente las controversias (siempre en un determinado contexto cultural ${ }^{8}$ ) resulta una categoría fundamental para comprender los métodos y estrategias de una y otra tradición probatoria, así como sus puntos de contacto y diferencias.

Para demostrar la afirmación precedente será necesario realizar una breve exposición del sistema de fuentes bajo medievales, con especial detención en la regulación probatoria en la Ley de Partidas, sus principios inspiradores y las reglas que derivan de la misma en el campo de la prueba. En un segundo momento, en tanto, haremos un análisis histórico hermenéutico de las Federal Rules of Evidence estadounidenses de 1975, para mostrar cuáles son sus principios inspiradores y reglas de prueba. Lo anterior nos permitirá comparar ambos sistemas y mostrar sus diferencias y sus semejanzas. De esta comparación, creemos, aparecerá con claridad que las semejanzas entre ambos sistemas expresan, más que una coincidencia, un vínculo necesario entre los principios y las reglas del derecho probatorio y los compromisos político-éticos presentes en los fines del proceso judicial, cuyo horizonte ha sido de manera constante la resolución pacífica de los conflictos.

\section{El PUNTO DE PARTIDA: TEXTOS NORMATIVOS DEL MEDIOEVO}

En un trabajo en extremo bien documentado, Antonio Pérez Martínº, ha

7 Mirjan Damaška ha subrayado a este respecto que, en contra de lo que habitualmente se piensa, los puntos de contacto entre la tradición continental y anglosajona del derecho probatorio son más significativos de los que se cree. Pero, a pesar de sus semejanzas, Damaška considera que en la actualidad el sistema probatorio anglosajón, bastante regulado, es incluso mucho más limitado que el sistema continental europeo en lo que respecta a un compromiso decidido por la denominada prueba libre, DAMAŠKA, Mirjan, El derecho probatorio a la deriva (traducción castellana de Joan Picó i Junoy, Madrid-Barcelona-Buenos Aires-São Paulo, Marcial Pons, 2015), pp. 33 in fine, 37-40.

${ }^{8}$ En este punto es posible ir incluso $\mathrm{m}$ á $\mathrm{s}$ a $\mathrm{t} \mathrm{r}$ á $\mathrm{s}$ y señalar que también en el ámbito de las ordalías se observa una conexión entre los fines del juicio y los mecanismos probatorios. El ejemplo de Oscar Chase sobre la tribu Azande, en África central, es elocuente a este respecto: su forma de determinar los hechos -el benge- no es racional en los términos modernos, dado que el rito de envenenar a un pollo, entregando a su vida o muerte la decisión del caso, nada dice respecto de si la demandada fue o no infiel, pero para efectos de dicha comunidad se trata de una solución justa y aceptable (por cuanto responde a sus creencias acerca de cómo deben hacerse las cosas) de modo que mantiene la paz social. CHASE, Oscar, Derecho, cultura y ritual. Sistemas de resolución de controversias en un contexto intercultural (traducción castellana de Fernando Martín Diz, Madrid-Barcelona-Buenos Aires, Marcial Pons, 2011), pp. 37-53.

9 Pérez Martín, Antonio, El ordo iudiciarius 'Ad summarian notitiam'y sus derivados, en Historia. Instituciones. Documentos, 8 (1981), pp. 195 ss. Su trabajo ofrece, además, un amplio panorama sobre los textos medievales sobre derecho probatorio general, entre los que se destacan: SCHENCK, Federicus, De probationibus, en Tractatus Universi Iuris (Venecia, 1584), IV, ff. 28v29r.; Lanfrancus de Oriano, De probationibus, en Tractatus Universi Iuris (Venecia, 1584), 
situado las bases normativo positivas del derecho procesal bajo medieval, en términos generales, en los siguientes textos: Instituciones 4,6, 4,8 y 4,13-18; Digesto 2, 3, 5.1, 11,1-2, 12,2-3, 22,3-6, 42,1-2, 43,1, 44,1-7, 48,1-2, 49,1-10; Código 2,1-13, 3,1-13, 4,19-21, 7,19, 7,42-70, 8,1, 9,1-7. Novelas 8, 20, 23, 41, 49, 50, 69, 79, 86, 93, 115, 124, 125, 134; Decreto C.2-C.6 y Decretales (Gregorio IX, Bonifacio VIII, Clemente V, etc.).

En lo que respecta al derecho probatorio, las fuentes formales más relevantes se encuentran en los siguientes textos: en el marco propio del derecho bajo medieval común, el Digesto, libro 12 numeral 3 (sobre el juramento), libro 22 numerales 3 (sobre la prueba en general y las presunciones), 4 (sobre los instrumentos) y 5 (sobre los testigos) y libro 42 numeral 2 (sobre la confesión); el Código, libro 4, 1 (sobre el juramento), 4, 19 (sobre la prueba en general), 4, 20 (sobre los testigos) y 4, 21 (sobre los instrumentos); y las Novelas, libros 47, 48, 49 (instrumentos y juramentos), 78 (seguridad de los instrumentos) y 90 (de los testigos).

Este primer grupo de textos (todos del siglo VI), tomados en su conjunto, revelan un interesante hecho: el sistema probatorio del derecho común bajo medieval de origen romano imponía al juez un compromiso ineludible tanto con la resolución pacífica de los conflictos como con la averiguación de la verdad de los hechos. En palabras de Walter Ullmann, "esta concepción del juez como un averiguador de la verdad iba de la mano con la idea de los juristas medievales de que el procedimiento judicial estaba guiado por el interés público. Lo público, afirmaban, tiene un compromiso en el mantenimiento del derecho y la justicia, y el medio a través del cual el derecho y la justicia habían de ser materializados era el juez: para alcanzar ese objetivo, sin embargo, al juez se le entregaba completa libertad para determinar cuál medio probatorio y cuál prueba consideraba necesaria y adecuada para dar por establecidos los hechos en disputa"10.

Esta libertad para la recepción y evaluación de la prueba, con todo, no estaba exenta de dificultades. Por una parte, la judicatura del período (anterior al siglo XII) se caracterizaba por su falta de formación disciplinar, es decir, en su mayoría se trataba de jueces legos ${ }^{11}$; por otra, aunque el juez era libre para determinar, recibir,

IV, ff. 33v-36r (con adiciones de Benedicto Vadis); Martinus De FAno, De negativa qualiter probanda, en Tractatus Universi luris (Venecia, 1584), IV, ff. 12rv.; y Franciscus Herculanus, De negativa probanda, en Tractatus Universi Iuris (Venecia, 1584), IV, ff. 12v-28v.

${ }_{10}$ Ullmann, Walter, Law and jurisdiction in the Middle Ages. An introduction to the sources of medieval political ideas (London, Variorum Reprints, 1988), p. 78 (XII).

${ }^{11}$ Como ha observado Luigi Ferrajoli, antes del advenimiento de la inquisición (siglos XII a XV), en el marco del derecho común y civil europeo la judicatura se encuentra básicamente compuesta por jueces temporales, jurados o pares de las partes, cuestión que, en un movimiento pendular que aún hoy perdura, cambia a partir del siglo XII con los procedimientos inquisitorios que exigen un juez versado en derecho: un docto sabedor de la ley (iudex illiteratur repellitur). Ferrajoli, Luigi, Derecho y razón (Madrid, Editorial Trota, 2014), pp. 574-576. Sobre el origen e influencia de los jueces legos en el sistema altomedieval, Nieva, Jordi, La valoración de la prueba (Madrid, Marcial Pons, 2010), especialmente el capítulo II, pp. 37-94; ÉL MISMO, La ciencia jurisdiccional: novedad y tradición (Madrid, Marcial Pons, 2016), pp. 49-69. En Chile se puede consultar una breve síntesis de este cambio de modelo (del juez lego al profesional) en ACCATINo, Daniela, La fundamentación de las sentencias: ¿un rasgo distintivo de la judicatura moderna?, en Revista de Derecho de la Universidad Austral, 15 (2003), pp. 10-14. 
diligenciar y evaluar la prueba, el interés público comprometido en su actividad, unido a los principios rectores de la actividad jurisdiccional misma, muy pronto hizo evidente una serie de dificultades para los sentenciadores. ¿Cuáles hechos son susceptibles de ser probados y cuáles no?, ¿quién puede testificar en un juicio?, ¿cuántos testimonios son necesarios para acreditar un hecho?, ¿qué valor ha de concederse a los diferentes tipos de testigos?, ¿cuántos tipos de instrumentos son admisibles en un juicio y qué valor ha de asignarse a ellos?, ¿en qué consiste una presunción y cuándo ésta puede ser derrotada?, etc.

En este contexto, la doctrina de los autores vino en auxilio de la precaria judicatura de la época que, a la sazón, ya comenzaba a explorar las relaciones entre el derecho romano (recuperado por aquel entonces) y el incipiente derecho canónico. Para los juristas de la época (siglo XII en adelante) los problemas recién descritos no eran en absoluto desconocidos, pues muchos de ellos además de académicos eran jueces o se desempeñaban como abogados y, por lo mismo, las preguntas precedentes les parecían no sólo interesantes desde un punto de vista teórico, sino sobre todo práctico. En este sentido, el derecho canónico en particular, en un trabajo legislativo que va desde el siglo XII al XIV, supuso un poderoso avance tanto para los jueces como para los abogados, dado que vino a cristalizar en unas disposiciones un tanto más claras las tendencias doctrinales dominantes en la práctica. En efecto, los textos normativos más relevantes en el horizonte del derecho canónico bajo medieval son, a nuestro juicio, el Decreto de Graciano, causas II a VI, en especial la causa III referida a los testigos (requisitos, exclusión y valor probatorio); las Decretales ${ }^{12}$ de Gregorio IX, libro II, títulos IX a XXIV; el Liber Sextus de Bonifacio (o Sexti Decretal), libro II, títulos IX a XI (sobre testigos y juramento); y el Decretal de Clemente V, libro II, capítulos VII a IX (de la prueba en general, testigos y juramento).

Con todo, pese a que estos textos ya presentan una s is te m a t i z a c i ó $\mathrm{n}$ estructural, en cuanto en ellos los juristas agrupan materias, la técnica regulatoria sigue siendo bastante pobre. En los hechos, se trata de conjuntos de soluciones particulares que por su aceptación general y la autoridad de la cual provienen se fijan como pautas de orientación al juez. No hay en estos textos, por lo menos no de manera explícita, una concatenación rigurosa, consciente y lógica de principios y reglas ordenados en libros, capítulos y parágrafos.

Este escenario cambia para la prueba con la primera gran sistematización temática bajo medieval: el Código de las Partidas de Alfonso X el Sabio ${ }^{13}$.

${ }^{12}$ Las Decretales de Gregorio IX merecen una atención particular ya que en esta obra es posible encontrar, por primera vez en los textos canónicos bajo medievales, un tratamiento sistemático de la prueba en general y de los medios probatorios en particular. Originalmente denominado Liber Extra, fue encargado a Raimundo de Peñafort, por aquel tiempo profesor en Bolonia, quien cumplió a cabalidad la tarea de reunir, organizar y sistematizar (en una línea de continuidad sucesiva con el Decreto), la actividad legislativa de los pontífices. Luego recibiría sendas glosas de Godofredo de Trani, Enrique Susa y Bernardo de Palma. Probablemente hasta la entrada en vigencia del moderno Código de Derecho Canónico de 1983, fue el texto de referencia dentro del Corpus Iuris Canonici.

${ }^{13}$ El término c ó d i g o lo usamos en un sentido general y no técnico, simplemente para referirnos a una sistematización ordenada de disposiciones jurídicas (en el caso de las Partidas, 


\section{Las Siete Partidas y su RÉGimen probatorio}

1. El contexto de las Siete Partidas: entre el derecho romano y el derecho canónico.

El código de las Siete Partidas (1256-¿63?), cuya redacción comenzó en el reinado de Alfonso X el Sabio, es considerado una de las obras jurídicas de mayor relevancia en Occidente. Cronológicamente el texto forma parte de una secuencia nomotética mayor que muestra el interés del rey sabio por dotar a Castilla (y al reino en general) de una legislación moderna (el texto, como es sabido, fue precedido por otros trabajos legislativos de Alfonso X: El Espéculo y El Fuero Real) ${ }^{14}$.

No es el propósito de esta investigación diseccionar el texto Alfonsino ni explicitar las deudas normativas y doctrinales del mismo. Sin embargo, sí nos parece necesario, antes de adentrarnos en la Partida Tercera (lugar propio, pero no exclusivo en la ley, del derecho probatorio) indicar en términos muy generales su contexto. En particular, los rieles conceptuales de naturaleza metodológica y normativa sobre los cuales esta obra se desplaza.

Desde un punto de vista metodológico el texto Alfonsino es tributario de la escolástica medieval, razón por la cual las inferencias predominantes en los razonamientos realizados en la obra (incluido los probatorios) son de índole deductiva. A su vez, el criterio rector de validación del o los enunciados principales en cualquier razonamiento es el principio de autoridad.

religiosa, moral y política también). Como ha señalado con mayor rigurosidad Alejandro Guzmán Brito, “con remoto y parcial origen en el siglo XVI, se desarrolló en Europa una forma de fijación hasta entonces inédita, distinta, en consecuencia, de la compilación, de la fijación de costumbres por escrito y de la fijación de la doctrina. Su nombre, como antes vimos, le fue impuesto sólo a principios del siglo XIX por Bentham. Por anticipación, pues ya para entonces denominamos 'codificación' al nuevo tipo de fijación. Sus primeros frutos comenzaron a verse en la segunda mitad del siglo XVIII y su desarrollo completo ya pertenece al siglo XIX; así que tardó buenos dos siglos y medio en cristalizar y unos tres en madurar”. GuZMán BRITO, Alejandro, La fijación y la codificación del derecho en Occidente (Valparaíso, Ediciones Universitarias de Valparaíso, 2017), p. 118.

${ }_{14}$ Para un estudio erudito, pormenorizado, y también polémico sobre la obra legislativa de Alfonso X, recomendamos el texto de Alfonso García-Gallo, La obra legislativa de Alfonso $X$. Hechos e hipótesis. De acuerdo con García-Gallo, un análisis riguroso histórico-documental "constata como ciertos unos hechos que difieren de los que hasta ahora han sido tenidos como indubitables. Así, entre otros, y como más significativos, la redacción de Espéculo a mediados de 1255, y su utilización legal; la del Fuero real en 1269, y no en 1255; la de las Partidas hacia 1290, y no en 1265 o 1263. En consecuencia, si se estiman probados tales hechos, la explicación de la obra legislativa de Alfonso X que se basa en la inexacta datación de tales obras queda carente de apoyo documental y no puede ser mantenida. Lo que obliga a buscar una nueva explicación que se ajuste a los hechos comprobados documentalmente; que la que se ofrece resulte o satisfactoria, es cuestión distinta; pero que no satisfaga no es argumento o prueba de que sea cierta la que se rechaza por falta de apoyo". García-Gallo, Alfonso, La obra legislativa de Alfonso $X$. Hechos e hipótesis, en Anuario de Historia del Derecho Español, 54 (1984), pp. 132-133. De manera consciente dejamos fuera el Setenario, obra probablemente comenzada por Fernando III y concluida (o no) por Alfonso X. Sobre los problemas asociados a la autoría y fechas de esta obra, véase MARTIN, Georges, De nuevo sobre la fecha del Setenario, en e-Spania. Revue interdisciplinaire d'études hispaniques médiévales et modernes (est éditée par CLEA), 2 (2006). Recurso disponible en: https://e-spania.revues.org/381\#authors. 
De esta manera, emulando a las sumas teológicas escolásticas ${ }^{15}$, que trabajan analíticamente los problemas (quaestio disputata) mediante la formulación de una o varias dificultades sobre el mismo (ad primum, secundum, tertium, etc., sic proceditur), para luego exponer una o varias tesis relevantes, generalmente favorables a la cuestión planteada (videtur quod), a la que se opone una o varias opiniones contrarias (sed contra) para luego arribar a una conclusión que hace las veces de premisa mayor para otras dificultades (respondo diciendum quod), las Partidas proponen para la afirmación de sus conclusiones el mismo método ${ }^{16}$. Esta forma de proceder del texto de las Partidas no debe llamar la atención, pues originalmente no fue pensado como un trabajo de derecho positivo y aplicación inmediata, sino como una suerte de e n c i clopedia ju ríd i c a (muy escolástica) para la comprensión y el estudio del derecho. Sólo a partir del año 1348, y por disposición de Alfonso XI de Castilla, las Partidas serán un cuerpo normativo de aplicación supletoria.

La aplicación del método escolástico (sobre todo en el uso y abuso del principio de autoridad) en el desarrollo y redacción de las Siete Partidas es una consecuencia natural del contexto que originó este código castellano: "Efectivamente, tratándose en las Siete Partidas de un cuerpo de leyes destinadas a regir una sociedad esencialmente cristiana, era obvio que el autor procurase establecer esas normas a base de las fuentes de la fe cristiana, sagrada escritura y tradición" ${ }^{17}$.

En cuanto al punto de vista normativo, las Siete Partidas representan una obra que es heredera del derecho común. Con derecho común nos referimos al "ordenamiento que emerge de los textos de las colecciones legales justinianeas redescubiertas en el s. XII, después de seis siglos de eclipse más o menos total o parcial, a los que pronto se sumaron los principales textos canónicos del primer milenio del cristianismo compilados por Graciano hacia el 1140-50, en su obra, que la posteridad denomina inicialmente decreta y luego decretum, y vigorosamente incrementados por las decretales o cartas pontificias y por los concilios generales

15 El género de las Sumas alcanzó tal vez su máxima expresión en la figura de Santo Tomás de Aquino. A propósito de la ley positiva o humana (que es el caso de las Partidas, por ejemplo), véase la aplicación que este filósofo hace del método en el Tomo VI. 1-2 q-91 a3. SANTO TOMAS DE Aquino, Suma Teológica, (Madrid, B.A.C., 1956), VI, cuestión 91, artículo 3º pp. 55-58.

${ }^{16}$ Un ejemplo concreto del método escolástico dentro de las Partidas lo tenemos en la Partidas 3, 3, 6, sobre el ejercicio de la abogacía por parte de las mujeres y la célebre Calfurnia. De acuerdo con el texto, "ninguna mujer, quanto quier que sea sabidora, non puede ser bogado en juyzio por otri. E esto por dos razones. La primera, porque non es quisada, nin honesta cosa, que la muguer tome officio de varon, estando públicamente embuelta con los omes, para razonar por otri. La segunda, porque antiguamente lo defendieron los sabios, por una mujer que decian Calfurnia, que era sabidora: porque era tan desvergonçada, que enojaua a los juezes con sus bozes, que non podian con ella. Onde ellos, catando la primera razon que diximos en esta ley, e otrosi veyendo que quando las mujeres pierden la verguença, es fuerte cosa el oyrlas, e de contender con ellas; e tomando escarmiento, del mal que sufrieron de las bozes de Calfurnia, defendieron que ninguna mujer non pudiesse razonar por otri". Citamos las Siete Partidas por la edición del licenciado Gregorio López de Tovar, en Los Códigos Españoles, Concordados y anotados (Madrid, Imprenta y Librería de la Publicidad, 1848). En adelante se citará esta obra como Partidas.

17 VÁzQUez JaneIro, Isaac, Las 'Auctoritates' escolástica en las Siete Partidas en Glossae, Revista de Historia del Derecho Europeo, 3 (1992), p. 65. 
de la Iglesia desde 1123 hasta 1311-1312, es decir, los cuatro primeros concilios lateranenses, los dos de Lyon y el de Vienne"18.

La recepción del derecho común en Castilla respondió a un conjunto de factores concomitantes que explican la opción legislativa de Alfonso X. Entre estos factores se cuentan su mayor desarrollo científico en comparación con los derechos nacionales; la copiosa cantidad de comentarios doctrinales a los textos de derecho romano y del derecho canónico a diferencia de la escasa producción de referencia sobre los textos locales; el hecho de que en las universidades europeas sólo se enseñara derecho común desde sus orígenes y que, por lo mismo, los juristas de entonces se formaran y adquirieran una estructura de pensamiento específica desde la cual interpretar los propios derechos locales (cuestión que se aplica también a los [posibles] redactores de las Partidas: Jacomé Ruiz o también Jacobo, llamado el de las Leyes; el maestre Fernando Martínez; el maestre Roldán, etc., todos presumiblemente formados en Bolonia, como tantos otros juristas de la península ibérica).

En razón de lo anterior, en las Partidas se advierte una gran influencia del derecho común, lo cual no supuso, por cierto, que se hubiese descartado el derecho local de los Fueros. Pero ahí donde uno y otro orden se hicieron incompatibles el derecho local cedió su lugar al derecho común. Incluso yendo más lejos, ahí donde el derecho romano se hizo incompatible con el derecho canónico, las más de las veces también aquél cedió el lugar a éste. Esto último ocurrió especialmente en las materias referidas a los sacramentos (como en el caso de régimen matrimonial) ${ }^{19}$.

Finalmente, cabe recordar que "en la literatura procesal se produce una influencia mutua entre canonistas y civilistas mucho mayor que en otros sectores. Los más antiguos ordines iudiciorum son obra de civilistas. Pero a la altura de la primera mitad del s. XIII, los canonistas habían tomado la iniciativa en esa materia, debido a las innovaciones que, sobre todo por obra de Inocencio III, se habían producido en el derecho canónico en materia procesal, innovaciones como la del proceso per inquisitionem, la prohibición de las ordalías, la exigencia de poner por escrito todas las actas de cada proceso, etc., innovaciones que no sólo se imponen en el proceso canónico, sino que poco a poco acaban siendo aceptadas en los tribunales seculares" ${ }^{\prime 2}$. Es probablemente debido a esto que en la tercera Partida se advierten todas estas influencias y desplazamientos de una manera intensa y constante.

Una vez trazados con alguna precisión los contornos teóricos (metodológicos y normativos) de los cuales se nutre la regulación de las Partidas conviene centrar la atención en su régimen probatorio.

18 García y García, Antonio, El derecho común en Castilla durante el Siglo XIII, en Glossae. Revista de Historia del Derecho Europeo, 5-6 (1993-94), p. 46.

19 Para un estudio detenido sobre las influencias y las fuentes romanas en las Partidas, véase Pérez Martín, Antonio, Fuentes romanas en las Partidas, en Glossae. Revista de Historia del Derecho Europeo, 4 (1992). Para el estudio de las fuentes canónicas de las Partidas y de los problemas teóricos que éstas representan, véase GARCía y GARCía, Antonio, Fuentes canónicas de las Partidas, en Glossae. Revista de Historia del Derecho Europeo, 3 (1992).

${ }^{20}$ García y García, Antonio, cit. (n. 18), p. 52. 


\section{El régimen probatorio de las Partidas. Principios y reglas}

Dado que el objetivo central de este estudio es identificar la conexión entre la tradición probatoria bajomedieval -en particular, de las Siete Partidas-y las ideas relevantes presentes en la Federal Rules of Evidence norteamericana-como ejemplo de la tradicional racional de la prueba-, centraremos nuestra atención ahora en los principios que informan el derecho probatorio en el código Alfonsino y en algunas de las reglas de prueba más relevantes presentes en el mismo.

En las Siete Partidas el principio rector del derecho en general es la realización de la justicia (título I, leyes 1-3). Sólo la justicia permite que un fallo judicial cumpla su cometido práctico: la resolución pacífica de las controversias. Pero la justicia del fallo no depende tan solo de la bondad de la ley, sino de la correcta interpretación y aplicación de la misma. De ahí la importancia fundamental de la prueba de los hechos.

En el ámbito específico del derecho procesal (tercera Partida y, en menor medida, también la séptima Partida, que regula materias penales), la realización de la justicia implica, por lo dicho anteriormente, la modelación estructural de todo el procedimiento; por ello no sorprende que esta idea se encuentre presente tanto en los requisitos y condiciones para el ejercicio de la judicatura como en el diseño de las reglas que han de disciplinar los procesos particulares ${ }^{21}$.

En el contexto del derecho probatorio, una condición sine qua non de la realización del fin primordial de los juicios es el de la averiguación de la verdad. En tal sentido, como telón de fondo al establecimiento y regulación de los diferentes medios de prueba se halla la búsqueda de la verdad de los hechos. En este sentido merece especial atención la ley 11 del título IV de la tercera Partida, cuyo título es elocuente: "de cómo los jueces deben escudriñar por todos los medios a su alcance para averiguar la verdad de los hechos en los pleitos en que intervengan".

Por la importancia del texto, vale la pena que lo citemos íntegramente: "Verdad, es cosa que los Judgadores deuen catar en los pleytos, sobre todas las otras cosas del mundo: e porende, quando las partes contienden sobre algund pleyto en juyzio, deuen los Judgadores ser acuciosos en puñar de saber la verdad del, por quantas maneras pudieren. Principalmente, por conoscencia que fagan por si mismos el demandor, e el demandado, en juyzio, o por preguntas que los juezes fagan a las partes en razon de aquellas cosas sobre que es la contienda. Otrosi por jura, en la manera que diximos en el titulo que fabla della. Porque quando por ninguna destas carreras non pudieren los Judgadores saber la verdad, han de recebir testigos, los que las partes traxeren para

${ }^{21}$ Esta idea ha sido captada de manera lúcida por Marta Madero cuando afirma que "en las Siete Partidas, la prueba ya no está solamente para ser útil, sino que se transforma en estrategia cognitiva compleja que impone a su vez una lectura de la realidad que depende de la precisión y la complejidad de la operación judicial”. De ahí que la prueba de los hechos en este contexto sea “una reconstrucción, consciente de dejar en el 'hecho' reconstruido las huellas de la operación que lo establece”. MADERO, MARTA, Causa, creencia y testimonios. La prueba judicial en Castilla durante el siglo XII, en Bulletin du Centre d'Oétudes médiévales d'Auxerre I BUCEMA (En ligne), Hors-série, 2 (2008), pp. 5-6 (disponible en: http://journals.openedition.org/cem/9672. Consultado por última vez: 04-04-2018). En el fondo lo que quiere hacer notar Madero es que en el código alfonsino el diseño probatorio determina el hecho probado que no necesariamente coincidirá con el hecho efectivamente acaecido. 
prouar sus intenciones, tomando la jura ante dellos paladinamente ante las partes, $e$ recibiendo despues los dichos de cada uno por si en poridad, e en logar apartado. E sobre todo, si por preuillejos, o por cartas valederas, o por señales manifiestas, o por grandes sospechas non la pudieren saber, deuen fazer en la manera que mostramos en las leyes deste libro, o en los logares do fabla en cada vna desta razones. E quando supieren la verdad, deuen dar su juyzio, en la menera que entendieren que lo han de fazer segund derecho" 22 .

La averiguación de la verdad en lo inmediato y la realización de la justicia en lo mediato demandan, a su vez, otros principios. Éstos, como hemos dicho, están presentes por igual en las condiciones para el correcto ejercicio de la judicatura y en el diseño de las reglas probatorias mismas. Dentro del primer grupo se encuentran los principios de imparcialidad (leyes 9-10), de racionalidad (ley 11) y de economía (ley 12); entre otros, contenidos en el título IV de la tercera Partida. Dentro de los segundos, en tanto, se hallan una serie de principios referidos a la determinación de los medios de prueba y a las reglas de ponderación de la misma (todos ellos los tomamos de la tercera Partida): fiabilidad (leyes 1, 2, 12, etc. título XIV), prelación (ley 32, título XVI) y oportunidad (leyes 1-2, título XV), entre otros.

De los principios recién aludidos es posible derivar un conjunto de reglas, que en el sistema de las Partidas son concebidas, en términos amplios, como "ley dictada breuemente con palabras generales, que demuestra ayna la cosa sobre que fabla; e ha fuerça de ley, fueras ende en aquellas cosas, sobre que fablasse alguna ley señalada de aqueste nuestro libro, que fuesse contraria a ella. Ca entonces, deue ser guardado lo que la ley manda, e non lo que la regla dize" ${ }^{23}$. Referidas a la prueba judicial, estas reglas indican los diferentes medios probatorios; la forma de diligenciarlos, y la manera de ponderarlos.

En el contexto de las Siete Partidas, la respuesta de parte (confesión espontánea o provocada), las cartas (instrumentos oficiales; pero también los que emanan de las partes), los testimonios y las presumpciones (aunque no son propiamente pruebas en el sentido técnico en que hoy usamos esta expresión) constituyen importantísimas pruebas directas. En la enumeración que realiza la ley 8 del título XIV de la tercera Partida, no se habla de las facultades de oficio del juez (interrogar e inspeccionar) ni de las declaraciones de expertos (consejeros), aunque del contexto del texto se sigue que también ellas son un importante medio de prueba directa ${ }^{24}$.

Entre los medios probatorios ofrecidos en las Partidas es el testimonio el que recibe una mayor atención, probablemente por ser el que más problemas presenta

22 Partidas 3, 4, 11

23 Partidas 7, 34.

${ }^{24}$ Los medios probatorios aparecen regulados en Partidas 3, 8, 14; si bien no se trata de una enumeración taxativa, las Partidas nombran la confesión de parte, los testigos verídicos y las cartas hechas por escribano. No se trata de una enumeración clausurada porque explícitamente el legislador de las Partidas estipuló que se puede probar un hecho por cualquier "otra cosa que deua ser creyeda, e valedera, así como se demuestra cumplidamente en las leyes de sus Títulos". Partidas 3, 14, 8. 
con respecto a la confianza en el correcto establecimiento de los hechos. Hasta cierto punto es paradójico que haya sido precisamente este rasgo de la prueba testimonial el que le permitiese (entre todos los medios probatorios) un desarrollo doctrinal y legislativo mayor ${ }^{25}$. En el código de las Partidas ello está muy claro: la prueba testimonial es el medio que recibe un tratamiento más detenido, tanto en lo que dice relación con las reglas de exclusión como de ponderación ${ }^{26}$.

Junto con la famosa ley 32 del título XVI de la tercera Partida, que establece el número de testigos para la acreditación de diferentes situaciones, este código contiene una constelación de leyes particulares que regulan la recepción y valoración de la prueba testimonial. Así, la ley 8 prescribe quienes pueden o no ser testigos, además de los criterios para la ponderación de los testimonios de personas de mal carácter y pública mala reputación (testigos condenados por falso testimonio); las leyes 12 a 15, a su vez, indican las razones de buen juicio para descartar los testimonios de parientes y siervos, por carecer de la imparcialidad necesaria en orden a alcanzar la verdad; la ley 22 duda de la veracidad del testimonio prestado por el enemigo de una de las partes; y la ley 29 indica el tipo de preguntas que el juez debe hacer a los testigos en orden a determinar la veracidad de sus dichos (todas estos casos se encuentran en el título XVI).

Una mención especial merece la ley 41 del mismo título y Partida, la cual resuelve con buen criterio la discrepancia entre testigos, señalando lo siguiente: "Ligeramente podria acaecer, que los testigos de la vna parte aduxesse, que se desacordarian en sus dichos, de manera que los vnos dirian el contrarios de los otros. E porende dezimos, que cuando assi acaeciere, que el Juzgador deue creer a aquellos que semejare que se acuestan mas a la verdad, e que acuerdan mas con el fecho, maguer que los otros fuessen mas: e non deue empecer a la parte el testimonio contrario, que

25 En el recuento que hace Antonio Pérez Martín sobre las obras de derecho procesal común (ius commune) en España, llama la atención el dispar tratamiento que reciben la prueba en general y los medios de prueba en particular. Mientras que de la prueba en general sólo se hace mención a cuatro textos (los Tractati de Probationibus de Schenck, De Oriano, De Fano y Herculanus); de la prueba instrumental en particular sólo se mencionan dos trabajos: los de Lanfrancus de Oriano (De instrumentorum fide et productiones) y de Paris de Puteo (De reassumptione instrumentorum). Este escenario varía significativamente cuando el erudito español pasa a enumerar los tratados sobre la prueba testimonial (De testibus), pues allí se alude a veintiún tratados de diversos autores. Pérez Martín, Antonio, El derecho procesal del 'Ius Commune' en España (Murcia, Ediciones de la Universidad de Murcia, 1999), pp. 36-37.

${ }^{26}$ Esto no significa que, a propósito de los otros medios de prueba consagrados en las Partidas, no exista una regulación interesante. Así, dentro de la confesión (conocencia-respuesta) es posible encontrar un conjunto de disposiciones sobre la forma en que ésta ha de ser realizada, el objeto de la misma y la posibilidad de retractarse. A ello se suma el principio general conocido como "a confesión de parte, relevo de prueba", incluso en materia criminal (Partidas 3, títulos 10 a 13). En cuanto a los instrumentos (cartas), las Partidas regulan la distinción clásica (instrumentos públicos y privados), las formalidades de cada carta en atención al acto que se pretende probar, además de señalar el valor probatorio de los instrumentos auténticos (plena prueba) y de los instrumentos privados (prueba en contra de quien los ha suscrito o sellado, Partidas 3 , títulos 18 a 20). Por último, tampoco descuida el legislador de las Partidas una consideración en orden al estándar de prueba, pues discierne con claridad entre las materias penales o criminales de las civiles, exigiendo respecto de las primeras un grado de prueba mayor al excluir la condena por gran sospecha o presumpcion (Partidas 3, 14, 12). 
los otros ouiessen dicho" ${ }^{27}$. Como se observa, aquí el sentenciador debe evaluar el testimonio de acuerdo con la verdad de los hechos, aunque la parte mayoritaria de los testigos no hubiese depuesto en tal sentido ("maguer que los otros fuessen mas”), de modo que esta disposición complementa a la ley 32 ya citada.

De lo expuesto hasta el momento resulta fácil colegir algunas ideas generales. En la tradición probatoria bajomedieval que converge en el código alfonsino es indispensable para la efectiva realización de la justicia que el fallo sea conforme a la verdad de los hechos. Para lograr este cometido, el régimen probatorio de las Siete Partidas se construye a partir de un conjunto de principios que se traducen en reglas probatorias de contenido racional, pero también moral. Estos principios y reglas originalmente servían como guías racionales para la interpretación y aplicación del derecho vigente (recuérdese que las Partidas sólo fueron derecho supletorio desde el siglo XIV en adelante). No se advierte, por lo anterior, en el texto de las Partidas un excesivo formalismo probatorio, toda vez que los medios de prueba no parecen estar enumerados de forma taxativa y su valor depende más bien de la verdad o correspondencia de los mismos con la realidad que del hecho de haber sido introducidos en el texto, tal como se ha ejemplificado en el párrafo precedente a propósito de la prueba testimonial.

Lo anterior permite notar que no se percibe una diferencia significativa entre los principios propuestos por la llamada tradición racional de la prueba (corrección de la decisión, averiguación de la verdad, realización de la justicia) con los que es posible advertir en las Siete Partidas. E incluso más, salvo algunas características (especialmente las referidas al cálculo de probabilidades, sujeción al derecho positivo y primacía absoluta de los valores epistemológicos en la fase probatoria), tampoco se percibe una gran disonancia entre las notas distintivas de la tradición racional de la prueba y la regulación medieval que comentamos. Esta es una cuestión interesante, toda vez que, como hemos visto, ambas tradiciones despliegan sus argumentos desde unos soportes teóricos bastante diversos e incluso, en algunos casos, inconmensurables entre sí. Por lo tanto, suponemos que existe a l g o (en ambas tradiciones) que explica la persistencia de unos mismos principios y unas reglas comunes que marcan una constante en el derecho probatorio, tanto del Common law como del Civil law.

En la sección que sigue, a fin de cumplir con el objetivo que nos hemos propuesto en este trabajo y explorar este a $\mathrm{g}$ o en común entre ambas tradiciones del derecho probatorio, acudiremos a las Federal Rules of Evidence de 1975 como un ejemplo conspicuo del acervo jurídico de la tradición racional de la prueba. El análisis de esta regulación nos permitirá demostrar en qué medida sus principios y reglas son (o no son), al menos en una parte significativa, congeniales con los principios y reglas de la tradición bajomedieval. El motivo de esta convergencia, ya lo hemos dicho, es que ambas regulaciones responden a la conexión conceptual entre los fines de la prueba y los fines del proceso judicial.

${ }^{27}$ Partidas 3, 16, 41. 


\section{LAS FEDERAL RULES OF EVIDENCE NORTEAMERICANAS:}

UNA REGULACIÓN PROBATORIA MODERNA

A diferencia de lo que sucedió con las Siete Partidas, la regulación estadounidense de la prueba judicial sí establece normativamente (como derecho positivo aplicable) un conjunto de disposiciones destinadas a regular las decisiones probatorias. Aunque llegar a ellas no fue un camino rápido y fácil. En efecto, la codificación de las reglas probatorias a nivel federal en los Estados Unidos de Norteamérica fue una iniciativa de la Judicial Conference que se inicia en 1961, cuando el Presidente de la Supreme Court, ChiefJustice Earl Warren, nombró un Comité especial sobre prueba para analizar la posibilidad y conveniencia de unificar en un solo código para las Cortes federales las doctrinas probatorias existentes ${ }^{28}$. El resultado de esta empresa se promulgó en 1975 como una regulación aplicable tanto a los procedimientos civiles (entendidos en un sentido amplio, por lo que se incluyen, por ejemplo, los juicios administrativos) como criminales (Rule 1101, b).

En términos generales, este cuerpo normativo refleja una tensión entre discrecionalidad y responsabilidad que es propia del derecho probatorio moderno. En este sentido, las FRE le reconocieron al juez una p o s i c i ón ú n i c a para valorar las pruebas (lo que justificó darle un margen de discrecionalidad) al mismo tiempo en que sus disposiciones consagraron un sesgo hacia la admis i b i l i d a d de la información a considerar (lo que apunta a la responsabilidad en la determinación de los hechos controvertidos) ${ }^{29}$.

En otras palabras, las FRE contienen múltiples cláusulas abiertas que guían normativamente las decisiones de los actores, al mismo tiempo en que favorecen la flexibilidad ante cada nuevo escenario. Se trata, por ende, de una variante del formalismo probatorio que se aleja de una discrecionalidad en sentido fuerte ${ }^{30}$.

Desde un punto de vista práctico, además, cabe añadir que las FRE fueron redactadas con el propósito de que tanto los jueces como los abogados actuasen en el campo de la prueba en el menor tiempo posible, empleando para ello una terminología que ya estaba enraizada en la práctica de los tribunales ${ }^{31}$.

\section{La relación juez/jurado. El pivote regulatorio}

Las FRE dan cuenta de un gran esfuerzo analítico por entender lo que hacen los diversos actores de la práctica probatoria y lo que acontece en los distintos momentos de la misma. Con todo, tal como lo denunciara tempranamente Ronald Allen, en principio esta regulación no tuvo demasiado en cuenta al binomio juez/ jurado. Este es un descuido que ha sido criticado con justo motivo, ya que casi

28 WeIssenberger, Glen, Evidence myopia: The failure to see the Federal Rules of Evidence as a codification of Common Law, en William and Mary Law Review, 40/5 (1999), p. 1567.

${ }^{29}$ LeOnard, David, Power and responsibility in Evidence Law, en Southern California Law Review 63 (1990), pp. 956-957, 967.

${ }^{30}$ Ibíd., pp. $974,985$.

${ }^{31}$ IMWINKELRIED, Edward, Moving beyond "top down" grand theories of statutory construction: A “bottom up" interpretive approach to the Federal Rules of Evidence, en Oregon Law Review, 75 (1996), pp. 395, 412-421. 
todas las decisiones sobre la prueba en la litigación estadounidense pasan por la relación juez/jurado. De acuerdo con el mismo Allen, lo apropiado habría sido regular la prueba atendiendo a las e $\mathrm{f}$ e ras $\mathrm{de}$ in fluencias entre el juez y el jurado, asumiendo que "los jurados deciden hechos que están íntimamente más vinculados a las partes, mientras que los jueces deciden hechos se ligan más íntimamente al sistema legal" 32 .

La observación general de Allen es que la primera tarea de una regulación moderna de la prueba judicial es descubrir qué relaciones son inherentes al campo que se regula y, como un segundo paso, ordenar dichas relaciones de una manera racional ${ }^{33}$. Esto implica reconocer que el derecho probatorio configura (también) un sistema de incentivos para crear, conservar y presentar pruebas, por lo que, más que una regulación que solo sirva para delinear fronteras dentro de un litigio, lo que un estatuto probatorio debe hacer es albergar c a m pos de fuerza que influyan -de diversas maneras- sobre quienes intervienen en la prueba ${ }^{34}$. Un ejemplo de esto en las FRE es la regla sobre declaración de oídas que permite acompañar como prueba en contra del empleador las afirmaciones que han hecho sus trabajadores, durante el trabajo y en relación con éste, considerando que es el empleador (y no un trabajador despedido o acosado, por ejemplo) quien tiene más acceso a las declaraciones de sus empleados (Rule 801, d, 2, D).

Esta imagen del derecho probatorio como una regulación flexible encuentra un decidido apoyo en uno de los miembros de la tradición racionalista, Charles Chamberlayne ${ }^{35}$, quien defendió a comienzos del siglo XX el rol del juez en la prueba utilizando el mismo argumento al que se ha acudido para defender el rol del jurado, esto es, el carácter democrático del derecho estadounidense. Para Chamberlayne: "La consecución de los objetivos que el moderno Derecho Probatorio [Law of evidence], como lo concibo, pretende servir, me parece incompatible con la relación inversa del juez y el jurado [...] Si esos intereses [de la sociedad por hacer justicia] han de ser bien servidos, es esencial que el [estamento] judicial sea revestido con poderes adecuados y en ningún sentido subordinado en importancia a un tribunal casual como el jurado, el cual [...] se siente completamente irresponsable por las amplias consecuencias de la litigación" 36 .

Esta defensa de los poderes del juez en el campo de la prueba tendría un correlato institucional con el tiempo, al desplazarse la noción de juez como un á r b itro pasivo (passive umpire) ${ }^{37}$ hacia un juez gestor (managerial

32 ALLEN, Ronald, The explanatory value of analyzing codifications by reference to organizing principles other than those employed in the codification, en Northwestern University Law Review, 79 (1985), pp. 1085, 1094.

${ }^{33}$ Ibíd., p. 1096 (afirmando que las FRE cumplieron bien la segunda tarea, pero dejaron algo de lado la primera).

${ }^{34}$ LeubSDORF, John, Evidence Law as a system of incentives, en Iowa Law Review, 95 (2010), pp. 1623, 1635-1656.

35 TwinInG, William, Rethinking, cit. (n. 1), pp. 65-69.

36 Chamberlayne, Charles, The modern Law of Evidence and its purpose, en American Law Review, 42 (1908), p. 771.

${ }^{37}$ Hazard, Geoffrey; Taruffo, Michele, American Civil Procedure. An Introduction (New Haven, London Yale University Press), pp. 89-90. 
judge ${ }^{38}$. Judith Resnik, por ejemplo, postuló que este cambio en la comprensión del papel del juez comenzó con una acción de responsabilidad civil, Parsons $v$. General Motors Corp., a raíz del choque de un vehículo que produjo la explosión inmediata de su tanque de gas lesionando al conductor. Este hecho dio lugar a una propuesta de discovery formulada por los abogados de las partes que resultó excesivamente extensa y costosa, y que pudo ser evitada, en definitiva, gracias al desempeño del juez a cargo ${ }^{39}$. Una cuestión así es posible porque la litigación civil estadounidense confía en la gestión del juez desde las etapas preparatorias del caso: por ejemplo, ante peticiones de discovery o disclosure (en las pre-trial conferences) y una vez iniciado el litigio principal, el juez puede ordenar de oficio una prueba testimonial e interrogar a los testigos (Rule 614, a, b), así como disponer que declare un experto cuando sea necesario para dictar sentencia (Rule 706, a).

La idea de regular la prueba tomando como pivote el binomio juez/jurado en un sistema como el estadounidense se conecta con una de las premisas de la tradición racional de la prueba, según la cual el contexto judicial modela las posibilidades del discurso probatorio. Así lo ha sostenido, por ejemplo, William Twining ${ }^{40}$. En la actualidad, esta premisa ha conducido a la teoría racional de la prueba a lo que podemos llamar una circunstancia de apertura del juicio de hecho. Esta apertura se expresa en una concepción de la prueba como un campo de estudio necesariamente multidisciplinario ${ }^{41}$, en donde adquieren especial fuerza los aportes de áreas del conocimiento diversas al derecho, en particular, la filosofía política y la epistemología ${ }^{42}$. Esto introduce desafíos y preguntas que no estuvieron presentes en las recopilaciones bajo medievales y de las cuales, por lo mismo, las Siete Partidas no se hicieron cargo.

\section{Evidence Law contemporáneo: Entre escepticismo, empirismo y regulación probatoria \\ El Evidence Law angloamericano es el lugar en donde la reflexión académica y práctica sobre la prueba judicial ha adquirido mayor intensidad ${ }^{43}$. En la actua- lidad, esta disciplina reconoce como un rasgo definitorio del juicio de hecho la necesidad de lidiar con problemas tanto normativos como epistémicos ${ }^{44}$. Pero no siempre fue así. A lo largo de los dos últimos siglos es posible identificar al menos}

${ }^{38}$ Pескнам, Robert, The federal judge as a case manager: The new role in guiding a case from filing to disposition, en California Law Review, 69/3 (1981), pp. 770 ss.

3985 FRE 744 N. D. Ga. (1980) analizado en RESNIK, Judith, Managerial judges, en Harvard Law Review, 96/2 (1982), pp. 386-391.

${ }^{40}$ TwInING, William, Evidence and legal theory, ahora, en ÉL MISMO, Law in Context. Enlarging a Discipline (Oxford, Clarendon Press, 1997), p. 114.

${ }^{41}$ Twining, William; SteIn, Alex, Evidence and Proof ([s.l., pero New York], New York University Press, 1992), XV; TwINING, William, Rethinking, cit. (n. 1), pp. 436-456.

${ }^{42}$ RoBerts, Paul, Rethinking the Law of Evidence: A twenty-first century agenda for teaching and research, en Current Legal Problems, 55 (2002), pp. 297 ss.

43 JaCKSON, John, Analysing the new evidence scholarship: Towards a new conception of the Law of Evidence, en Oxford Journal of Legal Studies, 16/2 (1996), pp. 309 ss.

${ }_{44}$ DAMAŠKA, Mirjan, Epistemology and legal regulation of the proof, en Law, Probabilities \& Risk, II, Yale Law School, Public Law Working Paper, 103 (2003), pp. 117-118. 
dos motivos -que aparentemente son opuestos entre sí- para relegar a una zona marginal las cuestiones normativas de la prueba: el escepticismo y el empirismo.

Jeremy Bentham fue tal vez el más claro exponente del recelo con respecto a la regulación de la prueba debido al escepticismo. Para Bentham, escéptico en cuanto a las reglas (rule-sceptic), pero no en lo referente al conocimiento de los hechos (fact-sceptic), carecemos de los soportes objetivos suficientes para dar con normas que puedan garantizar un juicio correcto, por lo que cualquier intento de formular reglas en materia de prueba deviene en un ejercicio de arbitrariedad y debe ser suprimido ${ }^{45}$.

Pero nótese que este escepticismo epistémico debe ser matizado mediante una distinción entre escepticismo y subjetividad. En este sentido, la reticencia de Bentham da cuenta de un escepticismo epistémico que no cae en el subjetivismo, dado que la crítica articulada por él en contra de las disposiciones legales en lo que se refiere a la prueba de los hechos no desconfía de la razón, sino que, por el contrario, se afianza en la posibilidad (aunque sea mínima) de apelar a criterios racionales. Tal como lo explica Thomas Nagel: "El escepticismo epistemológico tradicional depende de la objetividad de la razón: es siempre el resultado de llegar a la conclusión de que varias posibilidades alternativas incompatibles entre sí son todas igualmente compatibles con nuestra situación epistémica real, y de que es imposible, en consecuencia, decidir entre ellas sobre bases racionales. Por consiguiente, el escepticismo radical tiene que confiar en algunos pensamientos que no son puestos en duda y cuyo contenido objetivo se asume"46.

A estas alturas parece muy necesaria una relectura de las tesis benthamianas debido a que los análisis dogmáticos procesales y probatorios, al menos en el Civil Law, han tenido durante mucho tiempo una indesmentible "deuda con Bentham" ${ }^{47}$. Esta influencia, en cierto modo, les ha llevado a marginar el estudio de las reglas probatorias. La reflexión contemporánea sobre la prueba, en cambio, reconoce que en el Evidence Law hay una pugna entre escepticismo y racionalismo ${ }^{48}$, dentro de la cual la pregunta por la regulación probatoria adquiere un protagonismo que no puede ser soslayado.

Ahora bien, un segundo motivo para relegar la dimensión normativa de la prueba -lo que Alex Stein ha llamado la o la a b o li c i o $n$ is t a de su regulación- tiene que ver con la primacía del método empírico en los asuntos prácticos. Para saber lo que ha ocurrido no se requeriría de leyes, bastaría con el sentido común del juez: "Los avances científicos y tecnológicos atribuibles a este método han fomentado la confianza en las capacidades cognitivas humanas. También

45 Postema, Gerald, Fact, fictions, and law: Bentham on the foundations of evidence, en Fact in Law, (ed. por William Twining, Wiesbaden, Association for Legal and Social Philosophy, 1982), p. 37; TwInING, William, Rule-scepticism and fact-scepticism in Bentham's theory of evidence, en Fact in Law (ed. por William Twining, Wiesbaden, Association for Legal and Social Philosophy, 1982), pp. 67, 75-81.

46 Nagel, Thomas, La última palabra (traducción castellana de Paola Bargallo y Marcelo Alegre, Barcelona, Gedisa, 2000), p. 94.

${ }^{47}$ Pendás, Benigno, Jeremy Bentham: politica y derecho en los orígenes del Estado constitucional (Madrid, Centro de Estudios Constitucionales, 1988), p. 190.

48 Stein, Alex, Foundations (n. 3), pp. 56-63. 
han expuesto lo impracticable, sino injustificado, de los postulados metafísicos y de otro tipo de justificaciones del conocimiento. Casi todos los asuntos prácticos han pasado a ser gobernados por la distinción experimental de hipótesis factibles y no factibles. El valor de verdad de las hipótesis formuladas por las personas casi se ha identificado con su valor práctico, i.e., con la posibilidad de testearlas empíricamente. Este inductivismo empírico, frecuentemente tenido como el único racional, ha sido suscrito de forma abrumadora. Lo han adoptado no solo los científicos naturales, sino que también los sociales, los reformistas políticos, y la gente en general. Es el responsable de provocar la postura social descrita como 'confianza epistémica'"49.

Aquí es ilustrativo recordar nuevamente las tesis de Charles Chamberlayne, quien sostuvo que era necesario eliminar las reglas probatorias, pero no porque su existencia propiamente tal fuese cuestionable (por exceso de escepticismo o de empirismo), sino que debido a su rigidez. De acuerdo con Chamberlayne, las reglas probatorias son parte "del ámbito real de la doctrina del stare decisis", es decir, son "cánones de la administración judicial" en la medida en que el propio Evidence Law es "un modo o método para hacer algo": "visto así, las reglas de prueba, tanto las referidas a la admisibilidad como a la corroboración, pueden ser correctamente reguladas, en todos los casos, por la práctica local [...] o cambiarse de tiempo en tiempo, como en Inglaterra, por medio de la adopción por los jueces de las reglas de los tribunales" 50 .

Como se puede ver, tanto Bentham como Chamberlayne parecen estar de acuerdo en que acudir a reglas es útil, al menos, cuando se trata de una situación particular. Pero esta lectura utilitaria fue puesta en jaque con el desarrollo del Estado de Derecho moderno, pues dentro de una comunidad que se organiza de esta manera los repartos de riesgos de error que entraña el establecimiento judicial de los hechos deben descansar en reglas de aplicación general ${ }^{51}$.

Ahora bien, si la regulación de la prueba integra el ámbito del stare decisis, como sostenía Chamberlayne, conviene traer a colación el por qué esta imagen clásica del Common Law como un ordenamiento que progresa gracias a una nueva sentencia judicial que corrige las soluciones anteriores ya no resulta del todo satisfactoria. El problema con esta metodología radica en el peligro de darle al último fallo un exceso de representación, o sea, de suponer que será un fiel ejemplo de los futuros problemas suscitados sobre el mismo tema ${ }^{52}$. Los límites que tiene la disponibilidad heurística del juez representan un buen argumento para no entregarle a él la creación de reglas en el campo de la prueba. Esto no quiere decir, por supuesto, que las reglas legales no estarán expuestas ellas mismas al riesgo de ser sub-incluyentes o sobre-inclusivas, pero al menos dicho riesgo puede ser

49 STEIN, Alex, The refoundation of Evidence Law, en Canadian Journal of Law \& Jurisprudence, 9 (1996), pp. 282-283.

${ }^{50}$ Chamberlayne, Charles, cit. (n. 36), pp. 42, 764, 772 (destacado en el original).

51 Stein, Alex, Contra la "prueba libre", en Revista de Derecho de la Universidad Austral, 26/2 (traducción castellana de Jorge Larroucau, 2013), pp. 245 ss.

${ }^{5}$ SCHAUer, Frederick, Thinking Like a Lawyer. A New Introduction to Legal Reasoning ([s.l.], Harvard University Press, 2009), pp. 110-111. 
canalizado de mejor manera gracias a las herramientas que tiene el Parlamento y con las que no cuentan los tribunales. Para estos últimos, como ha dicho Larry Laudan, quedaría reservado el papel de ser un sistema de autocorrección de los errores que se cometen duran la solución de los $\operatorname{casos}^{53}$.

En definitiva, a pesar de los asedios del escepticismo y el empirismo, que tal vez no estuvieron presentes cuando se llevaron a cabo las regulaciones bajo medievales, el derecho probatorio moderno ha reconocido la importancia de contar con una regulación legal de la prueba. Esto responde, en nuestro argumento, a la conexión entre los fines de la prueba y los fines del proceso judicial; dicho vínculo puede resumirse con las palabras del juez Weinstein, quien a propósito de la litigación estadounidense de mediados del siglo XX sostuvo que las reglas procesales y las reglas de prueba son disposiciones que "además de establecer la verdad [...] deben procurar satisfacer una economización de recursos, inspirar confianza, apoyar políticas sociales independientes, facilitar la predicción y aplicación, contribuir a la eficiencia de todo el sistema jurídico, y tranquilizar a los litigantes" ${ }^{54}$.

Las FDE contienen principios y reglas que reconocen expresamente la búsqueda de estos fines - una decisión correcta, oportuna y eficiente del conflicto-, lo que permite ver en ellas, y a pesar de sus ostensibles diferencias, una continuidad en diversos niveles con las disposiciones del período medieval señaladas en la primera parte de este trabajo.

\section{Principios y reglas en las FRE}

Una vez que tenemos mayor claridad sobre los ejes teóricos y propósitos sobre los cuales se construyó el sistema de las FRE, corresponde que nos concentremos en los principios que las inspiran y las reglas en que los mismos se materializan. Esto nos permitirá advertir algunas zonas de contacto bastante apreciables entre estos principios y reglas con aquellos otros principios y reglas presentes en las Partidas.

En cuanto a los principios probatorios, conviene recordar una vez más que las FRE son una regulación que apostó por un puñado de disposiciones más o menos amplias en lugar de una codificación detallada ${ }^{55}$. En este sentido, sus cláusulas más importantes son las que reflejan sus fines - una solución justa, eficiente y oportunay principios - la búsqueda de la verdad en base a toda la información relevante-:

Rule 102: "Estas reglas deben interpretarse para administrar todo procedimiento de manera justa, eliminar gastos y retrasos injustificados, y promover el desarrollo del derecho probatorio, con el fin de establecer la verdad y asegurar una decisión justa” ("These rules should be construed so as to administer every proceeding

53 Laudan, Larry, Truth, Error and Criminal Law. An Essay in Legal Epistemology (Cambridge Studies in Philosophy and Law, Cambridge University Press, 2006), p. 207: "Un aspecto fundamental de cualquier sistema de investigación es que se trata de una obra en marcha. Las reglas que el sistema ha adoptado deben ser materia de revisión en forma constante, precisamente porque las normas actuales pueden ser sub-óptimas para alcanzar las metas deseadas".

${ }_{54}$ WEINSTEIN, Jack, Some difficulties in devising rules for determining truth in judicial trials, en Columbia Law Review, 66/2 (1966), p. 241.

55 Mengler, Thomas, The theory of discretion in the Federal Rules of Evidence, en Iowa Law Review, 74 (1989), pp. 459-466. 
fairly, eliminate unjustifiable expense and delay, and promote the development of evidence law, to the end of ascertaining the truth and securing a just determination").

Rule 402: "Admisibilidad general de la evidencia relevante. La evidencia relevante es admisible a menos que se establezca lo contrario: en la Constitución de Estados Unidos; en un estatuto federal; en estas reglas; o en otras reglas prescritas por la Corte Suprema. La evidencia irrelevante no es admisible" "General Admissibility of Relevant Evidence. Relevant evidence is admissible unless any of the following provides otherwise: the United States Constitution; a federal statute; these rules; or other rules prescribed by the Supreme Court. (2) Irrelevant evidence is not admisible").

Estas disposiciones subrayan la conexión entre la búsqueda de la verdad, la correcta decisión del caso y la necesidad de que los procesos judiciales reciban toda la información relevante. Como se puede advertir, se trata de principios plenamente compartidos con el Código Alfonsino, cuestión notable si se consideran los distintos trasfondos teóricos de ambos textos, aunque al hilo de nuestro argumento este tipo de coincidencias no resultan sorprendentes.

En cuanto a sus reglas, es interesante considerar que el mismo año en que se promulgaron las FRE, Jerzy Wróblewski-probablemente sin tener en cuenta su texto- ofreció desde una óptica analítica la siguiente clasificación de las disposiciones probatorias:

“(a) 'Reglas de evidencia jurídicas contra-empíricas' que conciernen a los hechos que no existen según el paradigma de la ciencia empírica aceptado (p. ej. la resistencia de la carne humana al fuego como una prueba de brujería) [...];

(b) 'Reglas de evidencia jurídicas para-empíricas' que se fundan en regularidades empíricas (p. ej. la presunción jurídica que atribuye la paternidad al marido de la madre en función del tiempo en que nació el niño) [...];

(c) 'Reglas de evidencia jurídicas ideológicas' que conciernen solamente a la carga de la prueba para defender algunos valores ideológicos aceptados en el derecho (p. ej. la presunción de inocencia, de buena fe) [...];

(d) 'Reglas de evidencia jurídicas no-empíricas' que, por fines jurídicos, determinan las consecuencias jurídicas de hechos que se presume han ocurrido en el tiempo t y en el espacio s establecidos arbitrariamente, cuando no se presenta una contra-evidencia (p. ej. el tiempo y lugar de la muerte de una persona declarara como muerta jurídicamente, cuando la embarcación en que la persona viajaba no ha llegado a ningún puerto en un tiempo suficientemente largo)" 56 .

Las FRE contienen ejemplos de cada una de estas categorías, salvo de las "reglas de evidencia jurídicas contra-empíricas", las que parecen ser un patrimonio exclusivo del período (primitivo desde el punto de vista contemporáneo) de las ordalías. Por ejemplo, la regla que permite acompañar copias de documentos a menos que surja un debate genuino acerca de su autenticidad (Rule 1003) es una "regla de evidencia jurídica para-empírica" ya que se funda en una regularidad:

56 WRÓBLEWSKI, Jerzy, El problema de la asi llamada verdad judicial, ahora, en ÉL MISMO, Sentido y hecho en el derecho (traducción castellana de Francisco Javier Ezquiaga y Juan Igartua, México D. F., Fontamara, 2001), p. 290. 
si nadie reclama de la autenticidad de una copia, ello se debe a que dicha copia es auténtica.

Por otro lado, el precepto que dispone que el intento de minimizar los daños de la víctima de un accidente no cuenta como una prueba de la responsabilidad por haber causado dichos daños (Rule 407) es una "regla de evidencia jurídica ideológica”, ya que neutraliza la máxima de la experiencia según la cual solo el responsable de un daño se preocuparía de repararlo. El valor que promueve esta regla tiene que ver con incentivar que tales daños sean mitigados por quien pueda auxiliar a la víctima.

Por su parte, la disposición que señala que la evidencia del hábito de una persona o la rutina de una organización, sea corroborada o no y aunque no haya testigos presenciales de la misma, es relevante para probar que la conducta de tal persona u organización en un caso particular coincidió con dicho hábito o rutina (Rule 406) puede ser considerada como lo que Wróblewski llamó una "regla de evidencia jurídica no-empírica”. Es decir que, a falta de una prueba en contrario, se debe presumir que la conducta en cuestión simplemente reitera un hábito o rutina de la persona.

En este sentido, la presencia de esta clase de preceptos y la ausencia de "reglas de evidencia jurídicas contra-empíricas" responde a que las FRE son un producto cultural que tuvo lugar dentro de la tradición racional de la prueba. Esto se reitera en muchas de sus disposiciones, partiendo, por ejemplo, por la que señala que las reglas probatorias deben prevenir el error en la toma de decisiones (Rule 103, 2, c) y continuando con aquellas que ponen el acento en la búsqueda de la verdad. Así, entre otras, las reglas que indican que los testigos deben declarar "verazmente" (Rule 603) sobre aquello respecto de lo cual tengan un "conocimiento personal" (Rule 602), de modo que las declaraciones de oídas son en principio inadmisibles como prueba del hecho controvertido (Rule 802).

Tal como se mostró en la primera parte, resulta admirable que las mismas reservas regulatorias las encontramos en la Tercera Partida del código alfonsino; justificadas allí, eso sí, desde una perspectiva escolástica y no desde los fundamentos teóricos de la tradición racional de la prueba.

Incluso los casos en que sí se aceptan las declaraciones de oídas pueden ser justificados a la luz de ambas tradiciones. Así, por ejemplo, aquel en que la declaración va en contra del propio interés del declarante (Rule 804, b, 3, A), es una disposición que se limita a consagrar una máxima de la experiencia según la cual alguien podría mentir para beneficiarse, pero nadie razonable mentiría para perjudicarse a sí mismo.

Otro caso en que se aceptan las declaraciones de oídas en las FRE es aquel en que dicho testimonio puede considerarse como la información que "más prueba" ("it is more probative") lo discutido (Rule 807, a, 3). Esta regla, como se puede ver, responde a una de las primeras tesis de la tradición racional de la prueba, según la cual los procesos judiciales deben ser capaces de identificar la mejor evidencia disponible para el caso. Durante el medioevo, la mejor evidencia en un juicio parece haber sido la confesión y, junto con ella, la prueba de testigos; con 
la modernidad, en tanto, cobró fuerza la prueba instrumental y, más adelante, la prueba científica y de expertos en general.

Siguiendo con las reglas de las FRE, en el mismo campo de la prueba testimonial, el interrogatorio del testigo debe orientarse a "establecer la verdad" (Rule 611 , a, 1) y la contraparte puede impugnar la credibilidad del testigo, pero no por cualquier motivo (Rule 608, a). Por ejemplo, lo puede hacer en base a que tal persona ha sido condenada por ciertos crímenes (Rule 609), pero no por sus creencias religiosas (Rule 610). Esta última advertencia es propia de una sociedad moderna -que no se inclina por una concepción de lo bueno-y habría sido inusual encontrarla en las recopilaciones medievales.

Como el jurado en un actor clave de la justicia estadounidense, las FRE señalan expresamente que se debe excluir la prueba sugestiva que lo afecte (Rule 103, 2, d), aunque la regla general del sistema sea la inclusión de toda información relevante, entendiendo por tal la que tenga "cualquier tendencia" a hacer la existencia del hecho controvertido "más probable o menos probable de lo que sería sin tal evidencia” (Rule 401, a). Si la información cumple con esta exigencia, debe ser considerada, a menos que concurra algún criterio específico de exclusión, esto es, que su valor probatorio es sustancialmente superado por el peligro de un daño injusto, genera confusión sobre la materia, induce a error al jurado, o bien, porque produce un retraso indebido, pérdida de tiempo o es sobreabundante (Rule 403).

Los fines de la prueba en la regulación estadounidense de 1975, entonces, coinciden con los fines del proceso judicial: la decisión no solo debe ser correcta, sino que también ha de ser oportuna y eficiente.

Dentro de la tradición racional el logro de estos fines depende en cierta medida de una regulación que se haga cargo de los problemas normativos del juicio de hecho, así como del uso adecuado de disciplinas no jurídicas, entre las que se destaca la epistemología. De allí, por ejemplo, que en los casos de los privilegios (como el secreto profesional entre abogado y cliente) las FRE exijan que ellos sean interpretados "a la luz de la razón y la experiencia" (Rule 501), o bien, que en el caso de la prueba pericial el experto deba emplear "principios y métodos confiables" (Rule 702, c).

En definitiva, es sumamente interesante que las FRE, que fueron pensadas en un contexto jurídico particular (el sistema del Common Law) y justificadas desde una concepción epistemológica concreta (la tradición racional de la prueba), afirmen, como hemos visto, principios y reglas congeniales con los contenidos en las Siete Partidas. Obviamente, esta comunión de ideas no puede ser justificada desde una perspectiva meramente epistemológica, o por lo menos no basta con dicho enfoque. Así las cosas, es necesario buscar en otro lugar este "algo" que hace posible que tradiciones probatorias diversas coincidan en sus nociones estructurales.

Nosotros creemos que este elemento modelador del derecho probatorio se encuentra en la frontera más remota de los fines propios del proceso judicial, especialmente, en la opción político-moral por (dentro del contexto cultural que corresponda) proporcionar las herramientas para que las partes en un litigio alcancen una solución pacífica. En este cometido, tanto en las Siete Partidas como en las FRE se observa la tensión entre la discrecionalidad judicial encaminada 
a la averiguación de la verdad de los hechos y la responsabilidad que le cabe al derecho por garantizar que en los diversos momentos de la prueba se observarán ciertos principios y se seguirán ciertas reglas que, incluso sacrificando el valor de la verdad en algunos casos, propenderán a la resolución justa, oportuna y eficiente del conflicto.

Si hay algo que las dos tradiciones analizadas en este trabajo enseñan es que, si bien es cierto que la justicia depende de la corrección del fallo, una sentencia correcta (i.e., de acuerdo con el derecho) no necesariamente ha de ser también verdadera en lo que se refiere a los hechos. En el caso de las Partidas, por ejemplo, a veces la mala fa ma o el gé n e ro de un testigo puede ser suficiente para excluir piezas de información relevantes con lo que cuestiones de naturaleza extraepistemológicas cobran más importancia que el descubrimiento de la verdad; en las FRE, a su vez, la salvaguarda de ciertas garantías constitucionales desactiva también las pretensiones epistemológicas. Y, sin embargo, por curioso que a un epistemólogo no familiarizado con las prácticas judiciales esto le pueda parecer, en uno y otro caso se puede arribar a un fallo correcto que, en tanto tal, contribuya a garantizar una convivencia pacífica.

\section{ConClusiones}

Como hemos tenido oportunidad de analizar en este trabajo sobre el régimen probatorio de las Siete partidas de Alfonso X el Sabio y las Federal Rules of Evidence norteamericanas de 1975, existen entre el sistema probatorio bajo medieval y la tradición racional de la prueba profundas diferencias teóricas, pero también grandes coincidencias prácticas.

Entre las diferencias teóricas (gnoseológicas y epistemológicas), el código alfonsino es tributario de un cierto realismo ingenuo que acepta de forma acrítica la realidad o que, incluso, discurre de espaldas a la misma en virtud de la aplicación del método escolástico y la apelación constante al principio de autoridad. Las FRE, por el contrario, redactadas en el marco de una tradición que ha debido lidiar fuertemente con el escepticismo y el empirismo, abrazan un realismo crítico que, en materia probatoria, se nutre de un elenco significativo de métodos propios de la ciencia moderna (aunque no exclusivos de ella): deductivos, inductivos, abductivos, estadísticos y probabilísticos.

Las diferencias teóricas y los contextos culturales de ambos textos explican también el diverso peso relativo que se le asigna a algunos medios probatorios en particular. En el sistema bajo medieval de las Partidas, la confesión/respuesta aparece como una prueba concluyente; en tanto que en el régimen de las FRE la prueba científica es la que actualmente tiene una indesmentible importancia.

También se advierten diferencias en cuanto a los compromisos político-morales en ambos documentos. Las Siete Partidas dan cuenta de una coincidencia verdadbien/verdad-justicia que se refleja en un fuerte influjo de la moral (teológica en dicho contexto) sobre las reglas de prueba. En las FRE, en cambio, se aprecia una cierta pretendida desagregación de los compromisos político-morales respecto de las cuestiones de naturaleza meramente probatoria, lo cual no ha impedido, 
de todas formas, que en varios aspectos las cuestiones políticas y morales primen sobre el enfoque epistémico.

Con todo, el propósito de este estudio no se limitó a dar cuenta de las diferencias entre ambos textos, sino que el argumento principal estuvo centrado en sus coincidencias. Por lo pronto, tanto el código de las Partidas como las FRE comparten, tal cual hemos visto, un conjunto de principios y reglas muy similares (idénticos en algunos casos). La explicación para ello, según nuestro punto de vista, dice relación con la dependencia conceptual del régimen probatorio respecto a los fines propios del proceso judicial; específicamente, el interés público comprometido en que la solución de los conflictos contribuya a una convivencia pacífica dentro de una determinada comunidad. De ahí, entonces, que en ambos sistemas la relación entre justicia y verdad oscile, en el sentido de que a veces la justicia se aleja de la verdad y en otras ocasiones no se separa de ella.

Estas coincidencias enseñan que los fines del proceso judicial en general (interpretado por el derecho procesal) y del derecho probatorio en particular, exigen, por lo menos en algún grado, una cierta regulación de las actividades probatorias. Tanto las Siete Partidas como en las FRE, a través de sus principios y reglas, sugieren que dicha regulación se incline por cláusulas abiertas que guíen normativamente las decisiones del juez (y/o del jurado o de quien tenga autoridad para juzgar los hechos) al mismo tiempo que favorezcan la flexibilidad ante nuevos escenarios. Los dos textos estudiados dan cuenta de la consagración -bajo paradigmas muy diversos- de un formalismo probatorio que se aleja de una discrecionalidad en sentido fuerte en materia de hechos para garantizar no sólo la búsqueda de la verdad sino la justicia en la solución de los conflictos.

\section{BiBLIOGRAFÍA}

AcCATINo, Daniela, La fundamentación de las sentencias: ¿un rasgo distintivo de la judicatura moderna?, en Revista de Derecho de la Universidad Austral, 15/2 (2003), pp. 9-35.

ALLEN, Ronald, The explanatory value of analyzing codifications by reference to organizing principles other than those employed in the codification, en Northwestern University Law Review, 79 (1985), pp. 1080-1096.

Anderson, Terence; Schum, David; TwInING, William, Análisis de prueba (traducción castellana de Daniela Accatino et al., Madrid-Barcelona-Buenos Aires-São Paulo, Marcial Pons, 2015), 463 pp.

Bentham, Jeremy, The Works of Jeremy Bentham (published under the Superintendence of his Executor John Bowring) (London, Simpkin, Marshall \& Co., 1843), VII.

Bentham, Jeremy, Treatise of Judicial Evidence by M. Dumont (London, Messrs. Baldwin, Cradock and Joy, 1825), 366 pp.

Chamberlayne, Charles, The modern Law of Evidence and its purpose, en American Law Review, 42 (1908), pp. 757-773.

Chase, Oscar, Derecho, cultura y ritual. Sistemas de resolución de controversias en un contexto intercultural (traducción castellana de Fernando Martín Diz, MadridBarcelona-Buenos Aires, Marcial Pons, 2011), 207 pp. 
DAмаŠKa, Mirjan, Epistemology and legal regulation of the proof, en Law, Probabilities \& Risk, II, Yale Law School, Public Law Working Paper, 103 (2003), pp. 117-130.

DAMAŠKA, Mirjan, El derecho probatorio a la deriva (traducción castellana de Joan Picó i Junoy, Madrid-Barcelona-Buenos Aires-São Paulo, Marcial Pons, 2015), 158 pp.

Ferrajoli, Luigi, Derecho y razón (Madrid, Trotta, 2014), 1024 pp.

García-Gallo, Alfonso, La obra legislativa de Alfonso X. Hechos e hipótesis, en Anuario de Historia del Derecho Español, 54(1984), pp. 97-161.

García y García, Antonio, El Derecho común en Castilla durante el Siglo XIII, en Glossae. Revista de Historia del Derecho Europeo, 5-6 (1993-94), pp. 45-74.

García y García, Antonio, Fuentes canónicas de las Partidas, en Glossae. Revista de Historia del Derecho europeo, 3 (1992), pp. 93-101.

GuZMÁn BRITO, Alejandro, La fijación y la codificación del derecho en Occidente (Valparaíso, Ediciones Universitarias de Valparaíso, 2017), 315 pp.

Hazard, Geoffrey; Taruffo, Michele, American Civil Procedure. An Introduction (New Haven, London Yale University Press), 240 pp.

IMWINKELRIED, Edward, Moving beyond "top down" grand theories of statutory construction: A "bottom up" interpretive approach to the Federal Rules of Evidence, en Oregon Law Review, 75 (1996), pp. 389-427.

JACKSON, John, Analysing the new evidence scholarship: Towards a new conception of the Law of Evidence, en Oxford Journal of Legal Studies, 16/2 (1996), pp. 309-328.

LAUDAN, Larry, Truth, Error and Criminal Law. An Essay in Legal Epistemology (Cambridge Studies in Philosophy and Law, Cambridge University Press, 2006), 238 pp.

Leonard, David, Power and responsibility in Evidence Law, en Southern California Law Review, 63 (1990), pp. 937-1013.

LEUbSDORf, John, Evidence Law as a system of incentives, en Iowa Law Review, 95 (2010), pp. 1621-1662.

Madero, Marta, Causa, Creencia y Testimonios. La Prueba Judicial en Castilla Durante el Siglo XII, en Bulletin du Centre d'Oétudes médiévales d'Auxerre I BUCEMA (En ligne), Hors-série, 2 (2008), 18 pp. (Disponible en: http://journals.openedition. $\mathrm{org} / \mathrm{cem} / 9672$. Consultado última vez: 04-04-2018).

Martin, Georges, De nuevo sobre la fecha del Setenario, en e-Spania. Revue interdisciplinaire d'études hispaniques médiévales et modernes (est éditée par CLEA), 2 (2006). Recurso disponible en: https://e-spania.revues.org/381\#authors.

Mengler, Thomas, The theory of discretion in the Federal Rules of Evidence, en Iowa Law Review, 74 (1989), pp. 413-466.

NAGEL, Thomas, La última palabra (traducción castellana de Paola Bargallo y Marcelo Alegre, Barcelona, Gedisa, 2000), 158 pp.

NievA, Jordi, La valoración de la prueba (Madrid, Marcial Pons, 2010), 374 pp.

NIEVA, Jordi, La ciencia jurisdiccional: novedad y tradición (Madrid, Marcial Pons, 2016), 749 pp.

PECKHAM, ROBERT, The federal judge as a case manager: The new role in guiding a case from filing to disposition, en California Law Review, 69/3 (1981), pp. 770-805.

PENDÁs, Benigno, Jeremy Bentham: política y derecho en los orígenes del Estado constitucional (Madrid, Centro de Estudios Constitucionales, 1988), 357 pp.

Pérez MarTín, Antonio, El derecho procesal del 'Ius Commune' en España (Murcia, Ediciones de la Universidad de Murcia, 1999), 288 pp.

Pérez Martín, Antonio, Fuentes romanas en las Partidas, en Glossae. Revista de Historia del Derecho Europeo, 4 (1992), pp. 215-246. 
Pérez Martín, Antonio, El ordo iudiciarius 'Ad summarian notitiam' y sus derivados, en Historia. Instituciones. Documentos, 8 (1981), pp. 195-266.

Postema, Gerald, Fact, fictions, and law: Bentham on the foundations of evidence, en Fact in Law, (editado por William Twining, Wiesbaden, Association for Legal and Social Philosophy, 1982), pp. 37-64.

ResNiK, Judith, Managerial judges, en Harvard Law Review, 96/2 (1982), pp. 374-448.

ROBERTS, Paul, Rethinking the Law of Evidence: A twenty-first century agenda for teaching and research, en Current Legal Problems, 55 (2002), pp. 297-345.

SAnto Tomas De Aquino, Suma Teológica (Madrid, B.A.C., 1956), IV.

SCHAUER, Frederick, Thinking Like a Lawyer. A New Introduction to Legal Reasoning ([s.l.], Harvard University Press, 2009), 239 pp.

Stein, Alex, Foundations of Evidence Law ([s.l., pero Oxford], Oxford University Press, 2005), 248 pp.

SteIn, Alex, Contra la "prueba libre", en Revista de Derecho de la Universidad Austral, 26/2 (traducción castellana de Jorge Larroucau, 2013), pp. 245-261.

STEIN, Alex, The refoundation of Evidence Law, en Canadian Journal of Law \& Jurisprudence, 9 (1996), pp. 279-342.

Twining, William; SteIn, Alex, Evidence and Proof ([s.l., pero New York], New York University Press, 1992), 552 pp.

Twining, William, Rethinking Evidence. Exploratory Essays (2a ed., [s.l., pero Cambridge], Cambridge University Press, 2006), 511 pp.

Twining, William, Evidence and legal theory, ahora, en ÉL mismo, Law in Context. Enlarging a Discipline (Oxford, Clarendon Press, 1997), pp. 89-109.

TwInING, William, Rule-scepticism and fact-scepticism in Bentham's theory of evidence, en Fact in Law (editado por William Twining, Wiesbaden, [s.1.], Association for Legal and Social Philosophy, 1982), pp. 65-84.

UlLmanN, Walter, Law and jurisdiction in the Middle Ages. An introduction to the sources of medieval political ideas (London, Variorum Reprints, 1988), 332 pp.

VÁzQuez JANeiro, Isaac, Las 'Auctoritates' escolástica en las Siete Partidas, en Glossae, Revista de Historia del Derecho Europeo, 3 (1992), pp. 65-92.

WeINSTEIN, Jack, Some difficulties in devising rules for determining truth in judicial trials, en Columbia Law Review, 66/2 (1966), pp. 223-246.

WeISSENBERGER, Glen, Evidence myopia: The failure to see the Federal Rules of Evidence as a codification of Common Law, en William and Mary Law Review, 40/5 (1999), pp. 1539-1593.

WRÓBLEWSKI, Jerzy, El problema de la asi llamada verdad judicial, ahora, en ÉL MISMO, Sentido y hecho en el derecho (traducción castellana de Francisco Javier Ezquiaga y Juan Igartua, México D. F., Fontamara, 2001), pp. 279-294. 
